\title{
Adaptability of sediment from Joumine reservoir, Tunisia, as a ceramic raw material
}

\author{
Masayoshi Fuji ${ }^{1}$ (D) Junzo Tsuchimoto $^{1} \cdot$ Chika Takai $^{1} \cdot$ Ryosuke Goto $^{1} \cdot$ \\ Mitsuteru Irie $^{2} \cdot$ Jamila Tarhouni $^{3}$
}

Received: 12 January 2017/ Accepted: 7 September 2017/Published online: 5 October 2017

(c) Springer International Publishing AG 2017

\begin{abstract}
Sediment occupies the storage capacity of reservoirs and reduces the sustainability of the surface water resource. A countermeasure is simply dredging, but this has often not been carried out because of financial reasons, especially in developing countries. One solution is to convert the sediment into a valuable commodity. This study examined the adaptability of the sediment in Joumine reservoir as a ceramic raw material. The sediment particles were plate-like in shape. Their size was around $0.5 \mu \mathrm{m}$, which is much smaller than the Japanese traditional ceramic raw material. The appropriate water content for forming was around $34.7 \%$. The shrinkage by drying was $10.73 \%$. The shrinkage by sintering was $0.17,1.24,9.35$, 14.72 , and $16.42 \%$ at $700,800,900,1000$, and $1150{ }^{\circ} \mathrm{C}$, respectively. The best sintering temperature was $900{ }^{\circ} \mathrm{C}$ from the viewpoint of density, porosity, and crystal structure. The shrinkage by sintering is much higher because of the small particle diameter of the sediment. The shrinkage is much higher than that of the common raw materials used in the traditional Japanese ceramic industry, but it is possible to adjust it by mixing at high temperature with a stable material such as sand or grained waste ceramics.
\end{abstract}

Masayoshi Fuji

fuji@nitech.ac.jp

1 Advanced Ceramics Research Center (ACRC), Nagoya Institute of Technology, 3-101-1, Honmachi, Tajimi, Gifu 507-0033, Japan

2 Alliance for Research on North Africa (ARENA), University of Tsukuba, 1-1-1, Tennodai, Tsukuba, Ibaraki 305-8577, Japan

3 Water Sciences and Techniques Laboratory, Institute of National Agronomy in Tunis (INAT), 43, Ave. Charles Nicoles, 1082 Tunis, Tunisia
Keywords Ceramics raw material $\cdot$ Sediment $\cdot$ Shrinkage Sintering · Clay

\section{Introduction}

Reservoirs that are constructed by stopping the fluvial flow are widely used as a reliable aquatic resource in all parts of the world. In particular, they are useful in arid lands with a large seasonal fluctuation in the rainfall. On the other hand, soil erosion during the rainfall is significant because there is little cover by vegetation in the river basin of the arid land. The minute suspended sediment carried by the stream flow is deposited in reservoirs and reduces their capacity.

The capacity loss of surface water resources by sedimentation in North African countries has reached $0.5 \%$ of the total storage capacity in Morocco, $0.5 \%$ in Algeria, and $1.0 \%$ in Tunisia per year (Remini 2006). Solutions to the sedimentation problem are indispensable to these arid countries which face a serious shortage of water.

In the case of Tunisia, although the problem of capacity loss due to sedimentation has been reported for a long time (Claude and Chartier 1977; Mammou and Louati 2007), according to a hearing of the Direction Générale des Barrages et des Grands Travaux Hydrauliques (DGBG/TH) in the Ministry of Agriculture of Tunisia, which manages all the reservoirs in Tunisia, dredging or other countermeasures have never been done because of financial reasons.

Irie et al. proposed the exploitation and use of the sediment; this would financially assist with the cost of dredging or other countermeasures against the sedimentation (Irie et al. 2011, 2013; Irie and Tarhouni 2014). One of the proposed exploitation methods is producing construction bricks. The exploitation of reservoir sediment as a material for construction bricks has already been evaluated 
in former studies from the point of view of physical properties (Chiang et al. 2008; Oya et al. 2002). However, the exploitation of sediment for brick production is not practical, for example, in Japan. One of the concerns about brick production using reservoir sediment is economic feasibility (Oya et al. 2003). In the case of Japan, the market for burned construction bricks is not very significant because the houses and buildings are constructed using wood or reinforced concrete. On the other hand, Mediterranean European countries and North African countries, such as Tunisia, have a big market for burned bricks because all the buildings are made of these. Although the application of several kinds of industrial wastes for brick production was evaluated (Ajam et al. 2009; Samara et al. 2009), reservoir sediment has not yet been tried.

Sediment occupies the storage capacity of reservoirs and reduces the sustainability of the surface water resource. One of the solutions is to convert the sediment to valuable commodities. To fabricate such valuable items, we have to control and design a ceramic process without any advanced treatments. It is essential to understand the properties concerning ceramics production, such as the shrinkage firing temperature, etc. In this study, the adaptability to ceramic raw material for fabrication of functional ceramics using the sediment from the Joumine reservoir has been examined from the point of view of ceramics science.

\section{Materials and methods}

\section{Materials}

The sediment was obtained from the bottom of the Joumine reservoir. The collected sample was brought with water. The sediment was dried at room temperature after water separation in a gypsum boule. The powder was ground by a mortar and dried at $200{ }^{\circ} \mathrm{C}$ for $2 \mathrm{~h}$ again to completely remove the physisorbed water (Fuji et al. 1997). The powder was kneaded while adjusting the amount of water to obtain plasticity by hand because the sample amount was not sufficient. The plasticity was judged from both the deformation of the spherical body and the adhesion to one's hand. The water content was determined after and before drying. The kneaded sediment was formed into a plate and the specimen cut out. The sample was sintered at several temperatures after drying. The linear shrinkage was measured both after drying and before and after sintering.

\section{Characterizations}

The particle size distribution was measured by a laser diffraction analyzer (MT-3000II; MicrotracBEL). The morphology and size of the sediment and the dried and sintered body were examined by a scanning electron microscope (JSM-7600F, JEOL Ltd.). The nitrogen adsorption-desorption isotherm of the sediment and dried and sintered body was measured at $77 \mathrm{~K}$ by an adsorption analyzer (BEL SORP-max, BEL Japan. Inc.), based on the specific surface area and pore size distribution calculated by the Brunauer-Emmett-Teller (BET) method. To confirm the crystal structure of the sediment before/after heating, and the dried and sintered body, X-ray diffractometry (XRD, Ultima V, Rigaku Co., Japan) was used in the range of $10-80^{\circ}$ at the scan speed of $2 \%$ min using $\mathrm{Cu}$ $\mathrm{K} \alpha$ radiation $(\lambda=0.1542 \mathrm{~nm}, 40 \mathrm{kV}, 40 \mathrm{~mA})$ and a proportional counter detector. Thermal changes were characterized by thermogravimetry/differential thermal analysis (TG/DTA, 8120, Rigaku Co., Japan). The samples were put in a Pt pan. Elemental analysis of the sample was performed by X-ray fluorescence (XRF, EDX-720, Shimadzu Co., Japan). The density of the body was measured on the basis of its weight and apparent volume.

\section{Results and discussion}

\section{Particle characterization of the raw ceramic material}

Figure 1 shows the field emission scanning electron microscopy (FE-SEM) images of the sediment after drying at $160{ }^{\circ} \mathrm{C}$ for $2 \mathrm{~h}$. The tiny plate-like particles consist of aggregates. The primary particle size is submicron. It seems that the size distribution is not very broad. Several samples were observed, and the results are almost the same. The results agree with those of a former study (Irie et al. 2012). According to the research results, the sediments sampled from four Tunisian dams did not contain pebbles and gravel which would cause cracks during the firing process. They also reported that the sediments were similar in distribution ranging from 0.5 to $50 \mu \mathrm{m}$. The clay $(<2.5 \mu \mathrm{m})$ contents were $27 \%$ in Joumine, $30 \%$ in Sejnane, $38 \%$ in Mellegue, $30 \%$ in Masri, and the remainder of each sediment was silt $(2.5-62.5 \mu \mathrm{m})$, while none of it was categorized as sand $(>62.5 \mu \mathrm{m})$.

Figure 2 shows an X-ray diffraction (XRD) pattern of the dried sediment. It is suggested that the sediment mainly contains calcite $\left(\mathrm{CaCO}_{3}\right)$, quartz $\left(\mathrm{SiO}_{2}\right)$, and kaolinite $\left(\mathrm{Al}_{2} \mathrm{Si}_{2} \mathrm{O}_{5}(\mathrm{OH})_{4}\right)$. The elemental analysis by X-ray fluorescence $(\mathrm{XRF})$ is shown in Table 1 . Most of the Ca comes from the calcite. One-third of the $\mathrm{Si}$ comes from the kaolinite, and the remainder is quartz. Al is assigned to kaolinite. Kaolinite contains around 10\%, but the XRD intensity of kaolinite is very weak. It is suggested that the kaolinite crystal structure is not uniform for efflorescence. 
Fig. 1 FE-SEM images of dried sediment from Joumine reservoir, Tunisia.

a Magnification $\times 500$,

b Magnification $\times 20,000$,

c Magnification $\times 50,000$
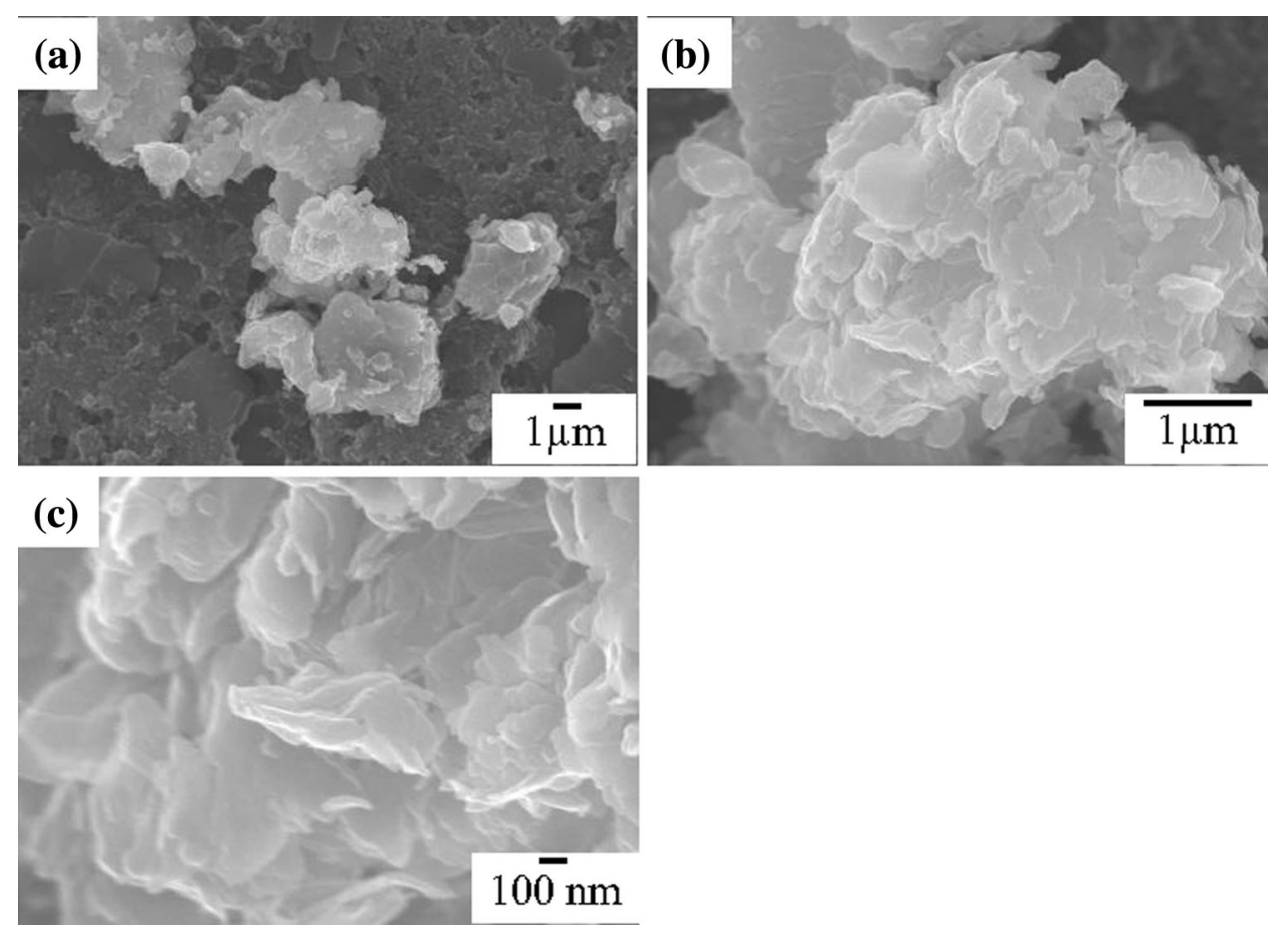

Fe and $\mathrm{K}$ would be contained in the kaolinite and/or quartz as an impurity, because the XRD pattern does not indicate any crystal that contains $\mathrm{K}$ and $\mathrm{Fe}$. On the basis of the results of both the $\mathrm{XRD}$ and $\mathrm{XRF}$, the sediment component

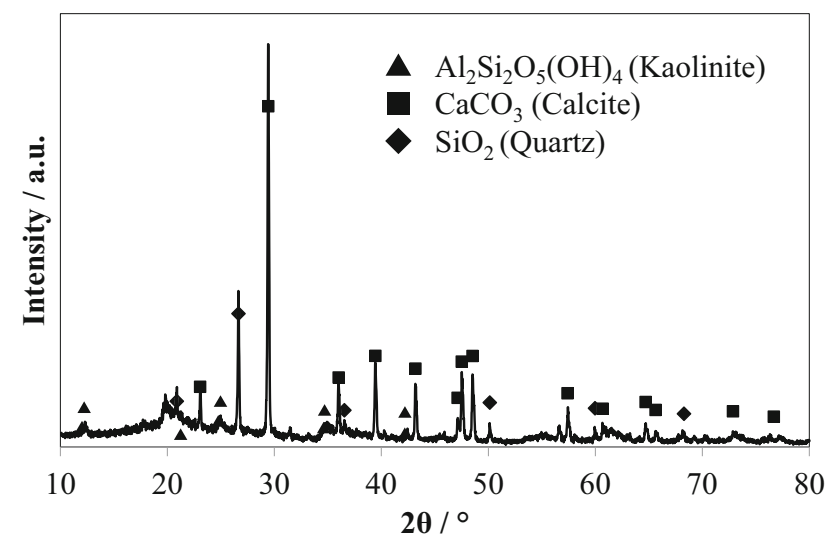

Fig. 2 X-ray diffraction pattern for the dried sediment

Table 1 Elemental analysis of sediment from the Joumine by XRF

\begin{tabular}{lcl}
\hline Element & At.\% & Mineral candidate \\
\hline $\mathrm{Ca}$ & 47.0 & $\mathrm{CaCO}_{3}$ \\
$\mathrm{Si}$ & 28.6 & $\mathrm{SiO}_{2} \cdot \mathrm{Al}_{2} \mathrm{Si}_{2} \mathrm{O}_{5}(\mathrm{OH})_{4}$ \\
$\mathrm{Fe}$ & 13.4 & $\mathrm{Impurity}$ \\
$\mathrm{Al}$ & 9.8 & $\mathrm{Al}_{2} \mathrm{Si}_{2} \mathrm{O}_{5}(\mathrm{OH})_{4}$ \\
$\mathrm{~K}$ & 1.35 & $\mathrm{Impurity}$ \\
\hline
\end{tabular}

is estimated to have 62.5 at.\% calcite, 25 at.\% quartz, and 12.5 at.\% kaolinite.

Figure 3 is the adsorption and desorption nitrogen isotherm of the dried sediment. The isotherm is the typical IV type based on IUPAC classification. The sediment has slittype pores from the shape of the hysteresis loop. It is caused by both the layer structure of kaolinite and platelike shape of the particle. The intensity of the XRD of kaolinite is weak, and the existence of kaolinite is based on the shape of the hysteresis loop. It is proposed that the crystal structure of kaolinite is not clear.

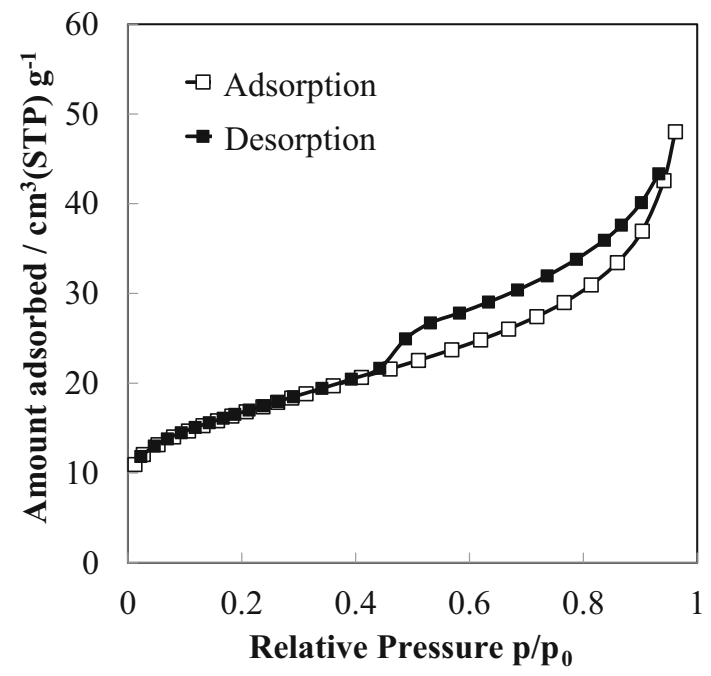

Fig. 3 Adsorption and desorption isotherms of nitrogen for the dried sediment. The type is IV based on IUPAC classification 
Figure 4 shows the results of the TG/DTA for the dried sediment. Figure 5 is the XRD patterns at several temperatures at which significant changes were observed during the thermal analysis. The large weight loss after $600{ }^{\circ} \mathrm{C}$ is caused by the decomposition of calcite to calcium oxide. This agreed with a former report (Arai 1995). The first weight loss with the endotherm is due to the removed water surrounding the particles and desorption of physisorbed water on the surface of particles. There is no difference in the XRD patterns between the dried sediment and that heated at $200{ }^{\circ} \mathrm{C}$ except for a decrease at $12^{\circ}$ which is assigned to the large interstices between the layers. The exothermic peak around $350{ }^{\circ} \mathrm{C}$ is due to the burning of organic substances, because the temperature almost agreed with the decomposition temperature by oxidation. The weight is several percentages and lower than the sediment from a Japanese reservoir because the basin has little vegetation. The exothermal peak around $350{ }^{\circ} \mathrm{C}$ overlapped the small endothermal peak with a weight loss.

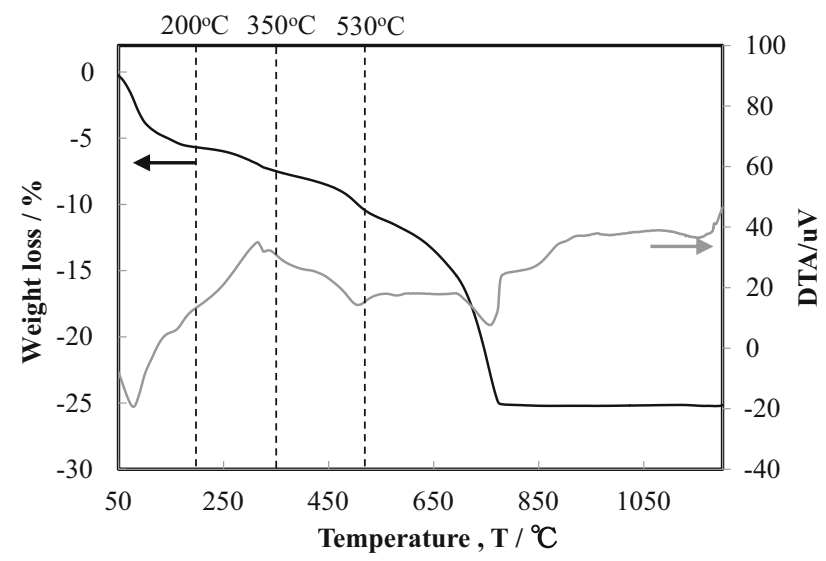

Fig. 4 TG/DTA profiles of sediment dried in air at a flow rate of $250 \mathrm{ml} / \mathrm{min}$

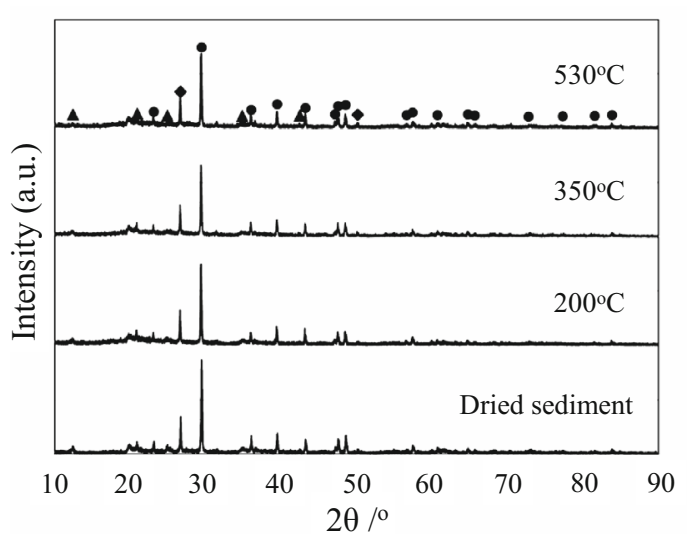

Fig. 5 XRD patterns of dried sediment and heat-treated at 200, 350, and $530{ }^{\circ} \mathrm{C}$; filled circle calcite, filled triangle kaolinite, filled diamond quartz
During that temperature change, a significant change in the XRD patterns between 200 and $350{ }^{\circ} \mathrm{C}$ occurred. The small peak would be the desorption of strong physisorbed water into the slit pores of the kaolinite. It is also indicated that an organic substance exists on the outer surface of the particles.

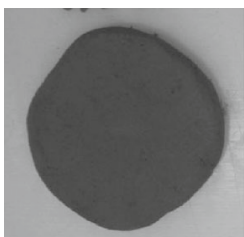

(a) soft

Water content

$=35.62$ mass.$\%$

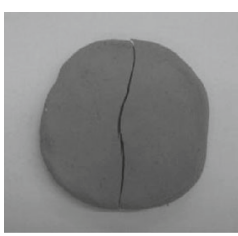

(d) after drying of (a)

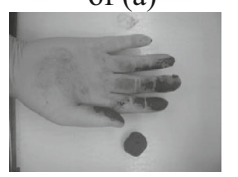

(g) adhesiveness to the hand of (a)

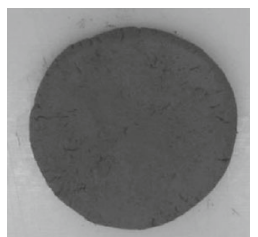

(b) good

Water content $=34.66$ mass.$\%$

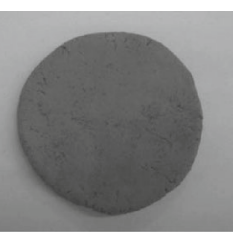

(e) after drying of (b)

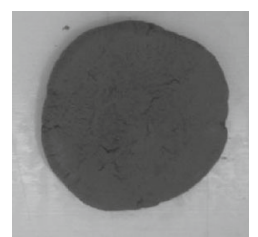

(c) hard

Water content $=31.88$ mass $\%$

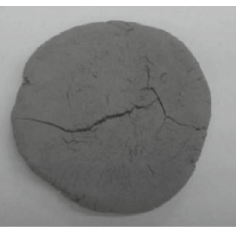

(f) after drying of (c)
Fig. 6 Kneaded sediment with different amounts of water, which decreases from a to c. d Example of the adhesiveness to the hand of the sample in $\mathbf{a}$. The adhesiveness was not observed in $\mathbf{b}$ and $\mathbf{c}$. $\mathbf{d}-$ f Results after drying samples in a-c, respectively. Cracks were not observed in $\mathbf{d}$ and $\mathbf{f}$

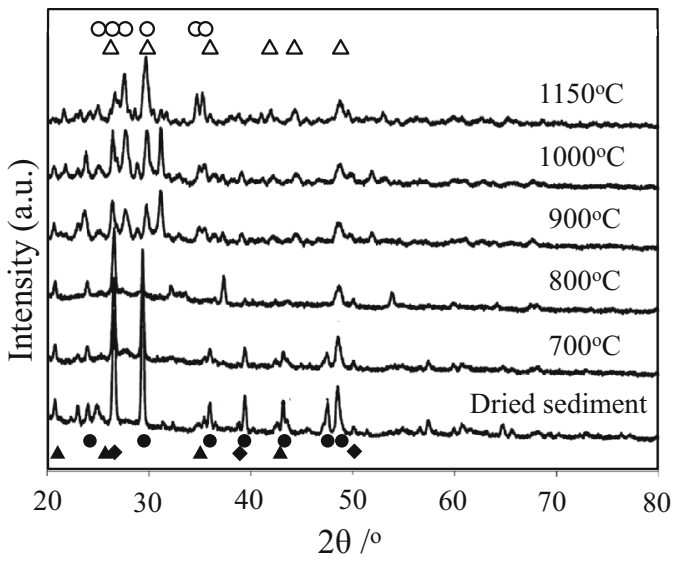

Fig. 7 XRD patterns of dried sediment and sintered at 100, 800, 900, 1000 , and $1150{ }^{\circ} \mathrm{C}$; filled circle calcite, filled triangle kaolinite, filled diamond quartz, open circle anorthite, open triangle mullite 
Table 2 Change of properties with sintering temperature

\begin{tabular}{llll}
\hline Sintering temp. $\left({ }^{\circ} \mathrm{C}\right)$ & Linear shrinkage $(\%)$ & Sintering temp. & Linear shrinkage $(\%)$ \\
\hline Dried & - & 2.28 & 57.2 \\
700 & 0.17 & 2.71 & 21.9 \\
800 & 1.24 & 2.81 & 10.7 \\
900 & 9.35 & 2.88 & 0.5 \\
1000 & 14.72 & 2.92 & 0.7 \\
1150 & 16.42 & 3.05 & 0.2 \\
\hline
\end{tabular}

On the basis of these results, the sediment is composed of calcite, quartz, and kaolinite. It contains a small amount of the organic substance. The particle size is several microns. From the point of view of material science, the contents are almost normal and good as a ceramic raw material except for the small particle size.

\section{Forming and firing characteristic}

In order to determine the amount of water required to obtain plasticity, the kneaded sediments are shown in Fig. 6. The hardness diminishes with increasing water content, since the moistest sample is the softest. Figure $6 \mathrm{~g}$ shows the adhesiveness of a sample to a hand, while samples in Fig. $6 \mathrm{~b}$ and $\mathrm{c}$ showed no adhesiveness. In comparison with the apparent deformed spherical formed bodies, the sample in Fig. 6a is very soft. Samples in Fig. $6 \mathrm{~b}$ and $\mathrm{c}$ exhibit no significant difference. After drying of the samples, the sample in Fig. 6b shrank, but there was no cracking as shown in Fig. 6e. On the other hand, samples in Fig. 6a and c had cracks as shown in Fig. 6d and f. From the results, the amount of water added to the sample in Fig. 6b is the optimal amount to afford good plasticity in the three samples. The appropriate water content for forming was around $34.66 \%$.

The results of sintering are shown in Table 2. The linear shrinkage of the samples increases with the sintering temperature. The density of the sintered body also increased. The shrinkage is relatively higher than that of the raw material of traditional Japanese ceramics (10\%) because of the small particle size of the sediment. The test piece is not large; therefore we can sinter the body without introducing cracks. However, when the sediment as the raw material is used as is, it would be difficult to obtain the sintered body with no cracking because of the high shrinkage. We should contain some particles with fire-resistance to prevent the large shrinkage.

The specific surface area significantly changed above $900{ }^{\circ} \mathrm{C}$. Figure 7 shows the XRD patterns of the sintered bodies. The pattern is remarkably changed at $900{ }^{\circ} \mathrm{C}$. The results indicated that densification occurred from $900{ }^{\circ} \mathrm{C}$. After $900{ }^{\circ} \mathrm{C}$, the pattern contains anorthite $\left(\mathrm{CaAl}_{2} \mathrm{Si}_{2} \mathrm{O}_{8}\right)$ and mullite $\left(3 \mathrm{Al}_{2} \mathrm{O}_{3} \cdot 2 \mathrm{SiO}_{2}\right)$ instead of kaolinite.
When one would like to fabricate dense ceramics, the best sintering temperature is $900{ }^{\circ} \mathrm{C}$ from the viewpoint of density. On the other hand, to obtain a porous material, the sintering temperature should be less than $900{ }^{\circ} \mathrm{C}$.

\section{Conclusion}

In this study, the adaptability of a ceramic raw material for fabrication of functional ceramics using the sediment from the Joumine reservoir was examined from the point of view of ceramics science. On the basis of the results, we conclude that the sediment can be used for ceramic raw materials as follows:

1. The contents of the sediment are mainly calcite $\left(\mathrm{CaCO}_{3}\right)$, quartz $\left(\mathrm{SiO}_{2}\right)$, and kaolinite $\left(\mathrm{Al}_{2} \mathrm{Si}_{2} \mathrm{O}_{5}(-\right.$ $\mathrm{OH})_{4}$ ). These are common ceramic raw materials, but the size is smaller. On the other hand, the amount of organic substances is low. This does not affect the firing such as making cracks, pores, and deforming.

2. The appropriate amount of water to obtain plasticity for forming is around $35 \%$.

3. The sintering temperature to obtain dense ceramics from the sediment is $900{ }^{\circ} \mathrm{C}$.

4. The shrinkage is $10.73 \%$ when drying and $9.53 \%$; when sintering at $900{ }^{\circ} \mathrm{C}$, that is much higher than for the ordinary raw material that is used in traditional Japanese ceramics, but it is possible to adjust by mixing at high temperature with a material stable such as sand or ground waste ceramics.

Acknowledgements This research was partially supported by Japan Society for the Promotion of Science (JSPS) KAKENHI Grant Number 25257306.

\section{References}

Ajam L Ben, Ouezdou M, Sfar Felfoul H, El Mensi R (2009) Characterization of the Tunisian phosphogypsum and its valorization in clay bricks. Constr Build Mater 23:3240-3247

Arai Y et al (1995) Handbook of cement, gypsum and lime. Gihodo Shuppan, Tokyo, pp 23-26 
Chiang K, Chien K, Hwang S (2008) Study on the characteristics of building bricks produced from reservoir sediment. J Hazard Mater 159:499-504

Claude J, Chartier R (1977) Mesure de l'nvasement dans les retenues de six barrages en Tunisie Campagne de 1975. Call ORSTOM ser Hydrol. 14(1):3-35 (in French)

Fuji M, Zhang J, Takei T, Chikazawa M (1997) Change in surface property of calcium carbonate by heat-treatment. Inorg Mater 4:330-336

Irie M, Tarhouni J (2014) Water reservoir as resource of raw material for ceramic industry. In Tunisia-Japan symposium: $R \& D$ of energy and material sciences, 596, 012003

Irie M, Kawachi A, Tarhouni J, Ghrabi A (2011) Development of sedimentation and characteristics of sediment on the reservoir in Tunisia. Annu J Hydrosci Hydraul Eng 55:163-168

Irie M, Kashiwagi K, Ujiie K, Nsiri I, Bouguerra S, Tarhouni J (2012) Feasibility of exploitation of the sediment in the reservoirs for the sustainability of surface water resource in Tunisia. J Jpn Soc Civil Eng Ser G 68(6):II41-II46
Irie M, Kawachi A, Nisiri I, Tarhouni J (2013) Observation of floodwater behavior and sedimentation in the reservoir. J Jpn Soc Civil Eng Ser B1 69(4):I_247-I_252

Mammou AB, Louati M (2007) Evolution temporelle de Tenvasement des retenues de barrages de Tunisie. Rev Sci L'Eau 20(2):201-211 (in French)

Oya M, Sumi T, Kamon M (2002) Characteristics of sediment in reservoirs and their utilization. J Jpn Soc Dam Eng 12(3):174-187 (in Japanese)

Oya M, Sumi T, Kamon M (2003) Cost analysis and feasibility study for PFI project on dam sediment recycling. J Jpn Soc Dam Eng 13(2):90-106 (in Japanese)

Remini B (2006) La Sedimentation Des Barrages. Universite, Saad Dahlab-Blida (in French)

Samara M, Lafhaj Z, Chapiseau C (2009) Valorization of stabilized river sediments in fired clay bricks: factory scale experiment. J Hazard Mater 163:701-710 